\title{
Editorial: Evolution: Education and Outreach goes open access!
}

\author{
Gregory Eldredge ${ }^{*}$ and Niles Eldredge
}

\section{Editorial}

It's a New Year and, with it, a momentous change for Evolution: Education and Outreach as we enter our sixth year of publication. From now on, we will be fully Open Access on our website (http://www.evolution-outreach. $\mathrm{com} /$ ). In addition, the first five previously published volumes - a total of 20 issues, most of them dedicated to particular topics (e.g. 'Co-evolution,' 'Biogeography,' 'Evolution and Medicine,' 'Museums and Evolution,' 'Human Evolution'), organized and written by experts in their fields - will be freely available, too, for the very first time on SpringerLink (http://link.springer.com). We'll keep publishing great articles on both evolution and education - including several new essays by evolutionary biologist Dan Brooks and paleontologist William Miller III, and many more excellent papers in the pipeline.

This move to Open Access is a dream come true. Everyone with a computer can have free and simple access to every contribution that we publish - now, in the future, as well as our past publications. We are, after all, an outreach journal, dedicated to facilitating the teaching and clear understanding of the total range of subject matter subsumed under the modern meaning of 'evolution.'

This means that everyone with an interest in evolution can now read our journal without being concerned about subscription costs, or needing to be affiliated with large academic institutions who routinely supply access to journals such as our own to their faculty, students and associates.

We continue to seek strong general-interest papers by scientists wanting to promote understanding of their research and areas of special interest and expertise, the better to inform everyone of the latest understanding and results in the evolutionary sciences. And, likewise, we continue our earnest efforts to publish the very best in evolutionary education research and theory, the better to share with the world the latest innovations in teaching evolution in the classroom.

The best news yet is that, although our journal will have a publication charge as is customary with open access journals (in our case, 1,250 euros), authors not affiliated with institutions that are themselves part of Springer's Open Access Membership Program (which would cover some or all of these publication costs) or authors who do not have other sources of funding to cover publication costs can apply to us for a waiver of the publication fee. We anticipate granting many such waivers to ensure that those without funding can continue to publish in our journal.

In short, we feel our readership will expand greatly as the word gets out about our new Open Access status. We hope, too, that this expanded readership base will in turn become authors of articles in Evolution: Education and Outreach. To our loyal readers and contributors of the past, our thanks for your continued interest in us. And to our new readers - and, we hope, contributors many thanks for joining us now as we gather momentum in our new status as an Open Access journal!

Received: 12 February 2013 Accepted: 13 February 2013

Published: 26 March 2013

\section{doi:10.1186/1936-6434-6-}

Cite this article as: Eldredge and Eldredge: Editorial: Evolution: Education and Outreach goes open access!. Evolution: Education and Outreach 2013 6:1.

\footnotetext{
* Correspondence: eldredge141@gmail.com

Division of Paleontology, American Museum of Natural History, New York, New York 10024, USA
} 